\title{
KINERJA KOLEKTOR TIPE PLAT DATAR PADA MESIN PENDINGIN ADSORPSI TENAGA SURYA DI KOTA MEDAN
}

\author{
Tulus Burhanuddin Sitorus \\ Departemen Teknik Mesin Fakultas Teknik, Universitas Sumatera Utara \\ PUI Energi Berkelanjutan dan Biomaterial, Universitas Sumatera Utara \\ Email: tburhanudin@yahoo.com
}

\section{Syahrul Abda}

Departemen Teknik Mesin Fakultas Teknik, Universitas Sumatera Utara

\begin{abstract}
The performance of a flat plate collector on adsorption refrigerator driven by the solar collector was investigated in the present work. Based on a study conducted no researcher studies the performance of solar collectors used in adsorption cooling system. The adsorbent used in the collector was $20 \mathrm{~kg}$ ordinary powder activated carbon of coconut shell produced in the Sumatera Utara province of Indonesia, 5 liters of methanol as adsorbate and 6 liters of water as the medium that was cooled. The experiments were carried out under varying weather conditions with total solar radiation about 12619-17807 kJ/m2/cycle in Medan city. The experimental results show that the values of collector efficiency obtained were about 52.11-53.92\%. The values of coefficient of performance (COP) obtained were in the range of 0.0318-0.0449. The results of the statistical study suggest that the effect of the weather conditions on collector efficiency thereabout $96 \%$.
\end{abstract}

Keywords: Adsorption Refrigeration; Flat Plate Collector; Medan City; Performance; Solar Energy.

\begin{abstract}
ABSTRAK
Kinerja kolektor plat datar pada mesin pendingin adsorpsi yang digerakkan oleh tenaga surya telah diteliti pada riset ini. Berdasarkan penelusuran studi yang dilakukan bahwa belum ada peneliti yang mengkaji kinerja kolektor surya yang digunakan pada mesin pendingin adsorpsi. Adsorben yang digunakan di dalam kolektor ini adalah jenis karbon aktif serbuk biasa dari cangkang kelapa yang diproduksi di provinsi Sumatera Utara Indonesia sebanyak $20 \mathrm{~kg}$, 5 liter metanol sebagai adsorbat dan 6 liter air sebagai media yang didinginkan. Pengujian dilakukan dalam berbagai kondisi cuaca dengan total radiasi matahari berkisar 12619-17807 kJ/ m²/siklus di kota Medan. Hasil eksperimen menunjukkan bahwa nilai efisiensi kolektor yang diperoleh adalah 52,11-53,92\%. Nilai koefisien performansi mesin pendingin adsorpsi yang diperoleh berada pada rentang 0,0318-0,0449. Hasil kajian statistik menyatakan bahwa besarnya pengaruh kondisi cuaca terhadap efisiensi kolektor adalah $96 \%$.
\end{abstract}

Keywords:Energi Surya; Kinerja; Kota Medan; Kolektor Surya Plat Datar; Pendingin Adsorpsi. 


\section{PENGANTAR}

Data dari Rencana Umum Energi Nasional Tahun 2015-2050 dan The International Energy Outlook 2006 menyatakan bahwa potensi energi fosil Indonesia yang meliputi: minyak bumi, gas bumi serta batubara hanya dapat bertahan selama 10 tahun, 31 tahun, dan 80 tahun dari saat ini bila tidak ditemukan cadangan energi fosil yang baru (Sitorus $d k k$., 2016). Kondisi ini kembali mengingatkan bangsa Indonesia bahwa usaha yang serius dan sistematis perlu segera dilakukan untuk mengembangkan dan menerapkan sumber energi terbarukan guna mengurangi ketergantungan terhadap bahan bakar fosil yang cadangannya semakin menipis. Penggunaan sumber energi terbarukan yang ramah lingkungan juga berarti menyelamatkan lingkungan hidup dari berbagai dampak buruk yang ditimbulkan akibat penggunaan bahan bakar minyak (BBM). Beberapa sumber energi terbarukan dan ramah lingkungan yang dapat diaplikasikan di tanah air seperti bioetanol, biodiesel, energi panas bumi, mikrohidro, energi angin, sampah/limbah, dan energi surya. Khusus untuk energi surya, perlu diketahui bahwa setiap tahun matahari memberikan energi sebesar $5,6 \times 10^{24}$ joule ke permukaan bumi melalui radiasi termal (Sitorus $d k k$., 2017). Energi termal matahari ini telah diaplikasikan khususnya untuk sistem pengeringan produk pertanian dan sistem pendinginan. Keberadaan energi surya cukup potensial di Indonesia dimana hal ini dapat dilihat dari posisi astronomi negara Indonesia di peta dunia. Letak Indonesia yang berada pada daerah khatulistiwa, yaitu pada $6^{0}$ Lintang Utara (LU) - $11^{0}$ Lintang Selatan (LS) dan $95^{\circ}$ Bujur Timur (BT) $-141^{\circ}$ Bujur Timur, dan dengan memperhatikan peredaran matahari dalam setahun yang berada pada daerah $23,5^{\circ}$ LU dan 23,5 LS maka wilayah Indonesia selalu disinari matahari kira-kira 2500 jam dalam setahun (Sitorus $d k k$., 2018). Karena letak Indonesia berada pada daerah khatulistiwa maka Indonesia memiliki tingkat radiasi matahari yang cukup tinggi. Diperkirakan rata-rata intensitas radiasi matahari yang jatuh pada wilayah permukaan Indonesia sekitar $4,8 \mathrm{kWh} / \mathrm{m}^{2}$ setiap harinya. Salah satu aplikasi dari pemanfaatan energi surya adalah mesin pendingin adsorpsi.
Mesin pendingin siklus adsorpsi terdiri dari komponen utama yaitu kolektor, kondensor, dan evaporator. Pada penelitian ini dikaji mengenai kinerja kolektor pada mesin pendingin adsorpsi tenaga surya karena komponen ini sangat berperan sebagai penyerap energi radiasi surya untuk menggerakkan sistem operasional mesin pendingin adsorpsi. Berdasarkan penelusuran studi yang dilakukan bahwa belum ada peneliti yang mengkaji kinerja kolektor surya yang digunakan pada mesin pendingin adsorpsi. Umumnya kolektor surya yang diteliti digunakan sebagai alat untuk pengering produk pertanian.

Kolektor surya merupakan tipe alat penukar kalor yang dapat mengubah energi radiasi matahari menjadi energi termal untuk aplikasi temperatur rendah seperti pada proses pendinginan adsorpsi, sistem pemanasan untuk air serta proses pemanasan pada industri tertentu seperti pengeringan (Duffie, 2006). Khusus untuk sistem pendingin adsorpsi, agar kolektor mampu bekerja secara optimum maka pada saat penyinaran atau proses desorpsi maka komponen ini harus mampu menghasilkan temperatur kolektor yang maksimum. Akan tetapi, di saat proses penyinaran selesai, kolektor ini harus mampu mencapai temperatur yang serendah mungkin untuk membuat proses adsorpsi berlangsung sempurna. Dengan kata lain, pada saat proses desorpsi di siang hari maka kerugian kalor yang dilepaskan kolektor harus seminimal mungkin. Akan tetapi, pada saat proses adsorpsi di malam hari maka kolektor harus mampu melepaskan kalor semaksimum mungkin. Kolektor surya yang digunakan pada penelitian ini adalah tipe plat datar (flat plate collector). Keuntungan utama dari kolektor surya tipe plat datar adalah dengan memanfaatkan kedua komponen radiasi matahari yaitu melalui sorotan langsung dan sebaran serta desainnya yang sederhana dengan sedikit memerlukan perawatan dan biaya pembuatan yang murah serta umumnya digunakan pada mesin pendingin adsorpsi tenaga matahari (Saman $d k k ., 2017$; Umair $d k k$., 2014). Umumnya kolektor jenis ini digunakan untuk memanaskan ruangan di dalam rumah, pengkondisian udara, dan proses-proses pemanasan dalam industri. Prinsip kerja dari kolektor surya tipe plat 
datar adalah dengan menyerap energi radiasi matahari dan memindahkan radiasi matahari tersebut ke adsorben yang terdapat di dalam kolektor. Radiasi matahari yang jatuh pada kaca penutup sebagian akan langsung dipantulkan, sebagian akan diserap, dan sebagian lagi akan diteruskan ke plat permukaan kolektor. Radiasi yang sampai pada permukaan plat akan diserap oleh plat kolektor. Panas yang diserap oleh plat kolektor digunakan untuk memanaskan adsorben yang terdapat di dalam kolektor.
Akibat panas yang diterima dari permukaan kolektor maka adsorbat atau refrijeran yang melekat pada permukaan adsorben akan terpisah dan mengalir menuju kondensor untuk mengalami proses kondensasi. Untuk mengurangi kerugian panas dari sisi dinding maka kolektor surya tersebut diisolasi dengan menggunakan bahan isolator yaitu kayu, Styrofoam, dan rockwool. Bentuk penampang kolektor surya yang digunakan dapat dilihat pada gambar 1.

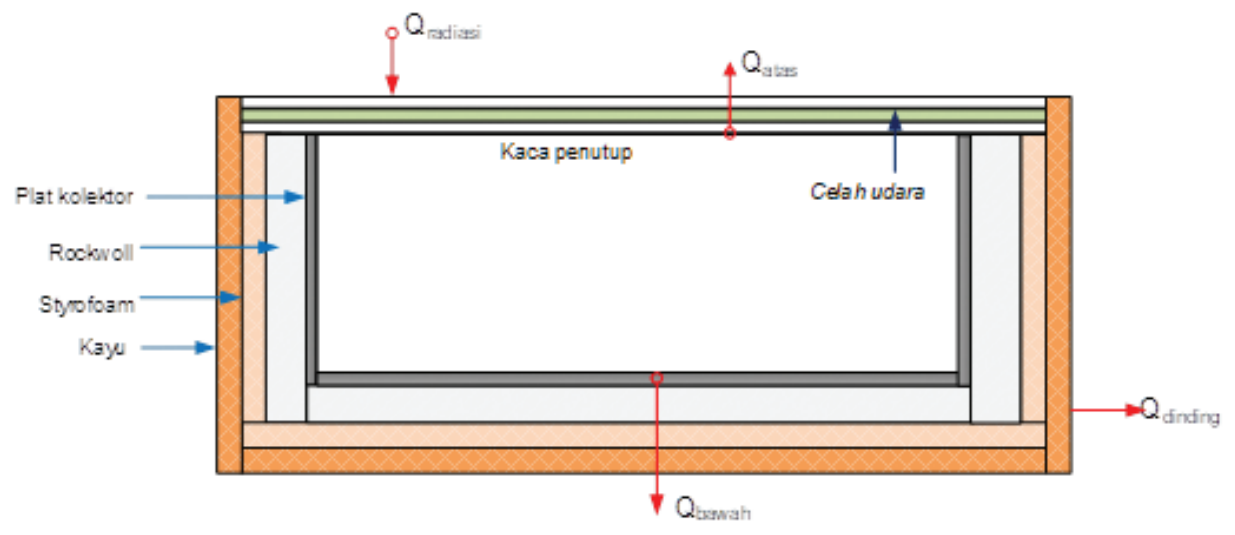

Gambar 1.

Penampang kolektor yang diuji

Kehilangan kalor total pada komponen kolektor surya tipe plat datar dapat ditentukan dari (Mahesh, 2017):

$\mathrm{Q}_{\text {total }}=\mathrm{Q}_{\text {dinding }}+\mathrm{Q}_{\text {bawah }}+\mathrm{Q}_{\text {atas }}+\mathrm{Q}_{\text {radiasi }}$

Efisiensi kolektor surya tipe plat datar dapat ditentukan dari persamaan (Kalogirou, 2009):

$$
c ̧=\frac{Q_{b}}{I \cdot A}
$$

Besarnya energi kalor yang digunakan didapatkan dari persamaan:

$$
\mathrm{Q}_{\mathrm{b}}=\mathrm{F}^{\prime} \times\left(\mathrm{Q}_{\text {masuk }}-\mathrm{Q}_{\text {total }}\right)
$$

dan

$$
\mathrm{Q}_{\text {masuk }}=\mathrm{I} \cdot \mathrm{A} \cdot \tau \cdot \mathrm{\alpha}
$$

Nilai $\tau$ menyatakan besarnya absorptivitas plat kolektor yang berwarna hitam sebesar 0,98, sedangkan faktor efisiensi kolektor $\left(\mathrm{F}^{\prime}\right)$ untuk kolektor tipe plat datar adalah $90 \%$. Di dalam kolektor diisi dengan adsorben yang massa optimumnya berkisar $20-26 \mathrm{~kg} / \mathrm{m}^{2}$ (Meunier, 1998). Kolektor ini harus tertutup, tidak tembus udara luar, dan memiliki pipa penghubung yang menjadi laluan refrijeran masuk dan keluar dari kolektor.

Menurut Saha $d k k$. ., (2007) bahwa ada empat pasangan utama adsorben. adsorbat yang umum digunakan dalam sistem pendingin adsorpsi tenaga matahari yaitu karbon aktif dan metanol, zeolite dan air, silika gel dan air serta karbon aktif dan amonia. Sedangkan untuk mengetahui karakteristik mesin pendingin adsorpsi maka perlu diketahui parameter utama yaitu nilai COP (coefficient of performance) yang dihasilkan. Besarnya nilai COP siklus adsorpsi sangat bergantung kepada kondisi cuaca dan efisiensi tiap komponen sistem terutama kolektor, kondensor, dan evaporator yang harganya bervariasi dari 0,01 hingga 0,2 (Fan, 2007; Wang $d k k$., 2009). Aplikasi dari mesin pendingin siklus adsorpsi ini dapat dibedakan 
atas tiga kategori yaitu untuk pendingin udara ruangan $\left(8-18^{\circ} \mathrm{C}\right)$, untuk refrijerasi makanan dan penyimpanan vaksin $\left(0-8^{\circ} \mathrm{C}\right)$, dan untuk proses pembekuan es dan tujuan pengentalan $\left(<0^{\circ} \mathrm{C}\right.$ ) (Mehdi $d k k ., 2015$; Li $\left.d k k ., 2005\right)$.

Besarnya nilai COP mesin pendingin adsorpsi tenaga surya dapat diperoleh dengan menggunakan persamaan (Watheq, 2008).

$$
\mathrm{COP}=\frac{\mathrm{Q}_{\text {pendinginan }}}{\mathrm{Q}_{\text {radiasi }}}
$$

Efek pendinginan $(\mathrm{kJ})$ dapat dinyatakan sebagai:

$\mathrm{Q}_{\text {pendinginan }}=\mathrm{m}_{\text {air }} \cdot \mathrm{C}_{\text {p-air }} \cdot\left(\mathrm{T}_{\text {air-max }}-\mathrm{T}_{\text {air-min }}\right)$

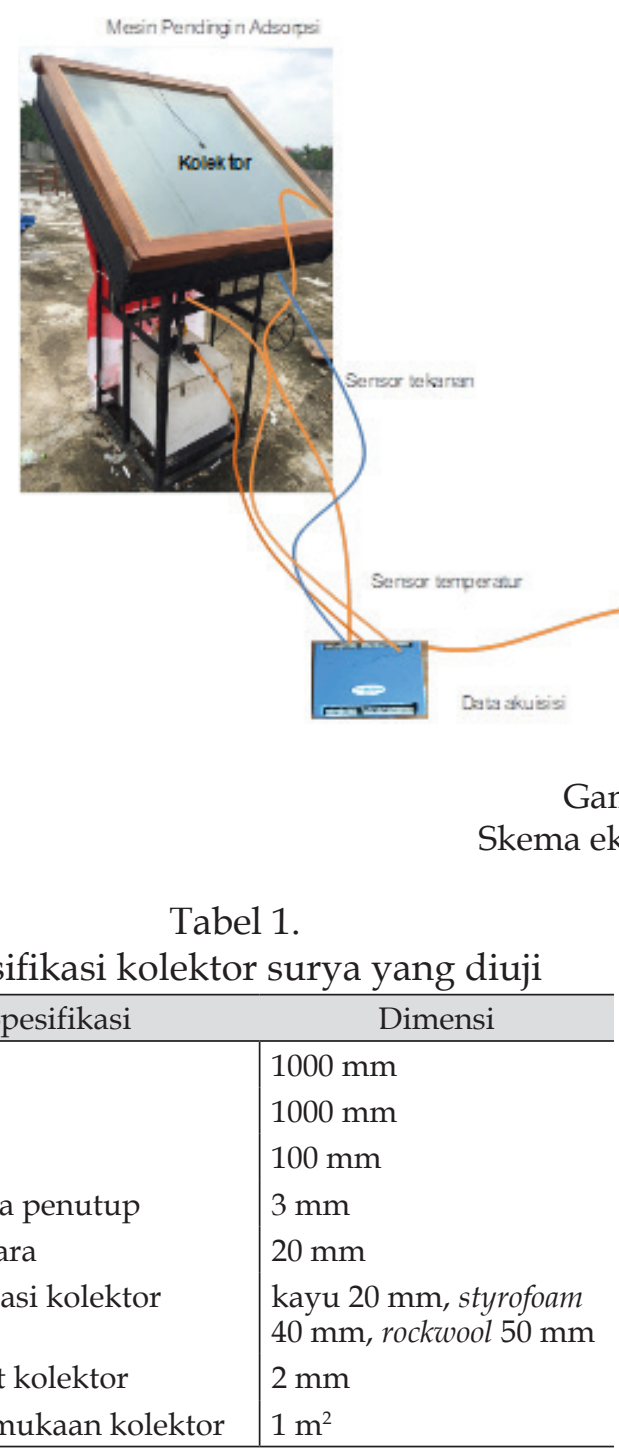

Besarnya energi radiasi yang diterima kolektor (kJ) adalah

$\mathrm{Q}_{\text {radiasi }}=\mathrm{I}_{\text {total }} \cdot \mathrm{A}$

dimana $I_{\text {total }}$ adalah radiasi total matahari selama satu siklus yang diperoleh dari hasil pengukuran dengan pyranometer $\left(\mathrm{kJ} / \mathrm{m}^{2}\right)$ dan A adalah luas permukaan dari kolektor $\left(\mathrm{m}^{2}\right)$. Kolektor memuat adsorben karbon aktif non-komersial jenis serbuk (powder) produk lokal dari cangkang kelapa (Musrowati $d k k$., 2014) sebanyak $20 \mathrm{~kg}$. Tabel 1 menampilkan spesifikasi dari kolektor tipe plat datar yang diuji. Refrijeran yang digunakan adalah metanol pro-analisis dengan kemurnian 99\% sebanyak lima liter. Volume air yang didinginkan pada penelitian ini sebanyak enam liter.

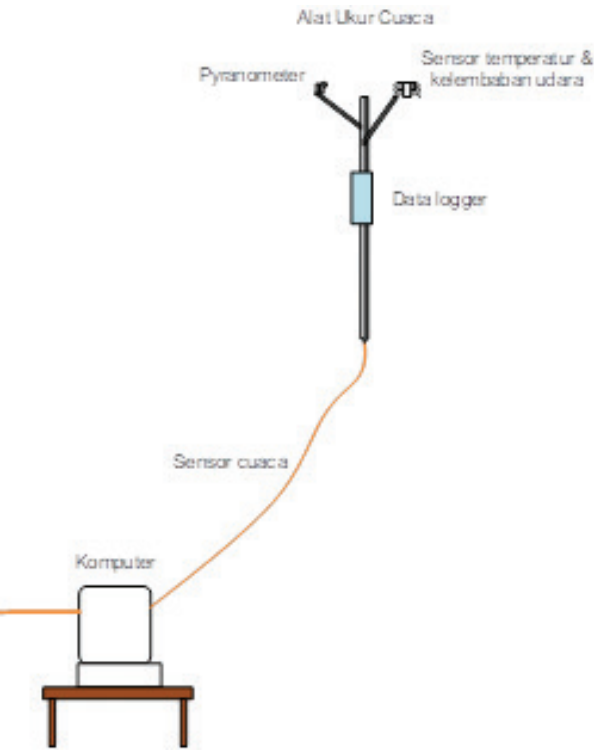

Gambar 2

eksperimental 
yang menggunakan 17 buah sirip dengan luas penampang perpindahan panas total $0.68 \mathrm{~m}^{2}$. Kolektor didinginkan oleh udara lingkungan secara konveksi alamiah. Evaporator dibuat dari baja tahan karat dan diisi dengan refrijeran metanol sebanyak 5 liter. Evaporator diletakkan di dalam kotak dingin (cold chamber) yang berisi air sebanyak 6 liter serta diisolasi dengan styrofoam dan rockwool.

Untuk menghubungkan kolektorkondensor-evaporator digunakan pipa fleksibel dengan diameter $20 \mathrm{~mm}$. Mesin pendingin adsorpsi dihubungkan dengan sebuah data akuisisi cole parmer melalui kabel termokopel tipe J dengan akurasi ketelitian $\pm 0,4 \%$ yang ditempatkan pada kolektor, kondensor, evaporator, dan air yang didinginkan. Sebuah data logger HOBO station digunakan untuk merekam kondisi cuaca yang meliputi intensitas radiasi matahari dengan pyranometer (akurasi $\pm 5 \%$ ), temperatur dan kelembaban udara dengan $\mathrm{T}$ (akurasi $\pm 0,2^{\circ} \mathrm{C}$ ), dan $\mathrm{RH}$ (akurasi $\pm 2,5 \%$ ) smart sensor. Alat ukur tekanan vakum digital Pace XR5 (akurasi $\pm 2 \%$ ) dipasang pada mesin pendingin untuk mengukur perubahan tekanan operasi yang terjadi. Semua proses pengukuran dilakukan setiap menit. Sebagai alat pendukung digunakan pompa vakum yang berfungsi untuk mengeluarkan udara yang terdapat di dalam mesin pendingin karena keberadaan udara mempengaruhi proses adsorpsi dan desorpsi yang terjadi. Variabel yang diamati dalam penelitian ini adalah kondisi cuaca yang terdiri dari intensitas radiasi matahari, temperatur udara, kelembaban udara sebagai variabel bebas serta efisiensi kolektor dan nilai COP sebagai variabel tidak bebas.

\section{HASIL DAN PEMBAHASAN Kondisi Cuaca Saat Pengujian}

Untuk kondisi pengukuran selama lima hari pengujian diperoleh besarnya energi radiasi matahari maksimum sebesar 17807, 36 $\mathrm{kJ} / \mathrm{m}^{2}$ pada siklus keempat. Radiasi matahari mulai terpantau pada alat ukur pyranometer berkisar di antara pukul 06.00 sampai dengan 06.25 WIB dan mulai tidak terpantau lagi diantara pukul 18.00 sampai dengan 18.30 WIB selama pengujian. Data pengukuran menunjukkan bahwa lama penyinaran radiasi matahari paling tinggi terdapat pada siklus kedua sebesar 12,47 jam/hari (52\%) dan paling rendah pada hari kelima sebesar 12,06 jam/ hari $(50,27 \%)$ selama pengujian berlangsung. Besarnya intensitas radiasi maksimum yang terjadi pada pengukuran tersebut umumnya terjadi pada pukul 11.55 WIB-13.44 WIB dan temperatur udara maksimum terjadi pada pukul 12.13 WIB-14.19 WIB. Untuk pengukuran ini, besarnya intensitas radiasi maksimum yang terjadi umumnya terjadi pada pukul 10.01 WIB12.10 WIB dan temperatur udara maksimum terjadi pada pukul 11.17 WIB-14.36 WIB. Gambar 3 menampilkan karakteristik radiasi surya selama pengujian.

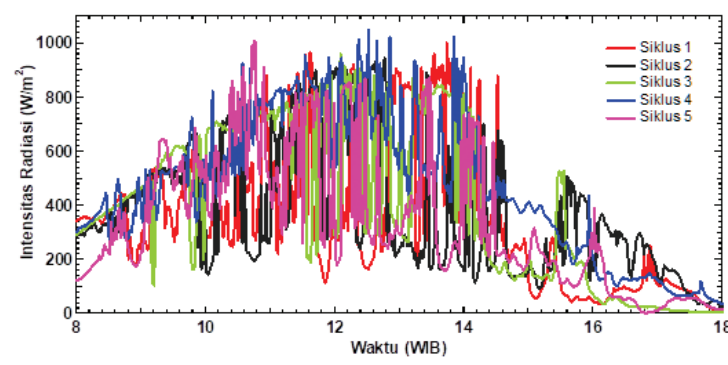

Gambar 3

Karakteristik radiasi matahari selama pengujian

Pengukuran kondisi cuaca dilakukan untuk setiap menit. Selama proses pengukuran yang dilakukan diperoleh intensitas radiasi maksimum sebesar 1048,10 W/m² yang terjadi pada siklus keempat. Tabel 2 menampilkan data rekapitulasi kondisi cuaca saat proses pengujian.

Tabel 2

Kondisi cuaca selama pengujian

\begin{tabular}{c|l|l|l|l|l}
\hline $\begin{array}{c}\text { Waktu penelitian } \\
\text { Maret 2018 }\end{array}$ & Siklus & $\begin{array}{c}\text { Radiasi rata-rata } \\
\left(\mathrm{W} / \mathrm{m}^{2}\right)\end{array}$ & $\begin{array}{c}\text { Lama penyinaran } \\
\text { (jam/siklus) }\end{array}$ & $\begin{array}{r}\text { Temperatur lingkungan } \\
\text { rata-rata }\left({ }^{\circ} \mathrm{C}\right)\end{array}$ & $\begin{array}{c}\text { Kelembaban relatif } \\
\text { rata-rata }(\%)\end{array}$ \\
\hline $1-2$ & 1 & 153,23 & 12,16 & 28,68 & 84,09 \\
$2-3$ & 2 & 167,03 & 12,46 & 29,27 & 80,99 \\
$3-4$ & 3 & 179,31 & 12,35 & 27,85 & 84,26
\end{tabular}




\begin{tabular}{c|l|l|l|l|l}
\hline $\begin{array}{c}\text { Waktu penelitian } \\
\text { Maret 2018 }\end{array}$ & Siklus & $\begin{array}{c}\text { Radiasi rata-rata } \\
\left(\mathrm{W} / \mathrm{m}^{2}\right)\end{array}$ & $\begin{array}{l}\text { Lama penyinaran } \\
\text { (jam/siklus) }\end{array}$ & $\begin{array}{c}\text { Temperatur lingkungan } \\
\text { rata-rata }\left({ }^{\circ} \mathrm{C}\right)\end{array}$ & $\begin{array}{c}\text { Kelembaban relatif } \\
\text { rata-rata }(\%)\end{array}$ \\
\hline $4-5$ & 4 & 206,10 & 12,33 & 29,59 & 67,25 \\
$5-6$ & 5 & 146,06 & 12,06 & 27,09 & 85,79 \\
\hline
\end{tabular}

Untuk pengujian kinerja mesin pendingin dilakukan mulai dari jam 08.00 WIB pagi sampai dengan 08.00 WIB besok paginya. Proses pengujian dilakukan masing-masing sebanyak lima siklus dimana satu siklus lamanya 24 jam.

\section{Performansi Kolektor Surya Tipe Plat Datar}

Komponen yang sangat berpengaruh pada mesin pendingin siklus adsorpsi tenaga surya adalah kolektor atau sering juga disebut dengan adsorber. Kolektor yang digunakan pada penelitian ini adalah tipe plat datar yang menggunakan kaca penutup. Gambar 4 menampilkan pola distribusi temperatur pada kolektor selama pengujian. Tampak bahwa pada proses pengujian selama 24 jam terjadi fluktuasi temperatur di permukaan kolektor. Temperatur kolektor maksimum umumnya terjadi antara pukul 12.00-14.00 WIB. Kondisi ini tentunya turut dipengaruhi oleh jumlah radiasi surya yang diterima permukaan kolektor setiap saat.

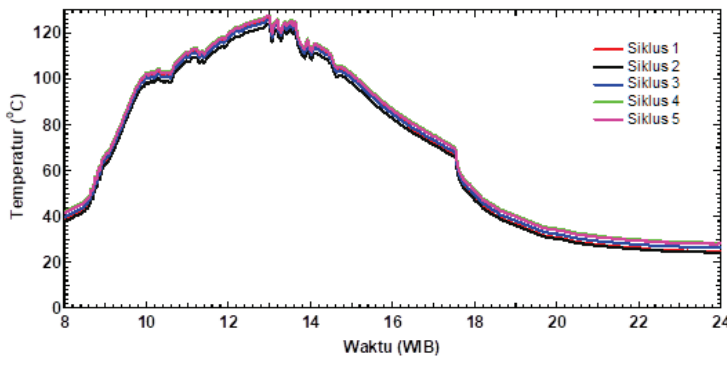

Gambar 4

Pola distribusi temperatur pada kolektor selama pengujian

Berdasarkan data hasil pengukuran dan perhitungan yang dilakukan maka diperoleh besarnya kerugian kalor pada sisi atas, bawah, dan dinding kolektor serta efisiensi kolektor surya tipe plat datar selama pengujian seperti yang ditampilkan pada tabel 3 .

Tabel 3

Efisiensi kolektor surya tipe plat datar selama pengujian

\begin{tabular}{l|l|l|l|l|l|l}
\hline \multicolumn{1}{c}{$\begin{array}{c}Q_{\text {dinding }} \\
(\mathrm{W})\end{array}$} & \multicolumn{2}{c}{$\begin{array}{c}\mathrm{Q}_{\text {bawah }} \\
(\mathrm{W})\end{array}$} & $\begin{array}{c}\mathrm{Q}_{\text {atas }} \\
(\mathrm{W})\end{array}$ & $\begin{array}{c}\mathrm{Q}_{\text {radiasi }} \\
(\mathrm{W})\end{array}$ & $\begin{array}{c}\mathrm{Q}_{\text {masuk }} \\
(\mathrm{W})\end{array}$ & \multicolumn{2}{c}{$\begin{array}{c}\mathrm{Q}_{\text {berguna }} \\
(\mathrm{W})\end{array}$} & $\begin{array}{c}\eta_{\text {-kolektor }} \\
(\%)\end{array}$ \\
\hline 1.684 & 2.037 & 170.161 & 301.299 & 1253.868 & 700.818 & 53.13 \\
1.480 & 1.897 & 163.143 & 292.383 & 1188.079 & 656.258 & 52.51 \\
1.321 & 1.537 & 165.282 & 302.209 & 1203.743 & 660.054 & 52.12 \\
1.592 & 2.069 & 174.113 & 307.919 & 1313.391 & 744.929 & 53.92 \\
1.604 & 2.117 & 184.968 & 305.771 & 1264.895 & 693.391 & 52.11 \\
\hline
\end{tabular}

Berdasarkan pengujian yang telah dilakukan, diperoleh nilai efisiensi kolektor surya berkisar dari 52,11\% hingga 53,92\%. Besarnya nilai efisiensi kolektor dipengaruhi oleh beberapa parameter seperti radiasi matahari yang diterima kolektor, luas permukaan kolektor, dan kerugian kalor total. Kaca penutup kolektor yang digunakan terdiri dari dua lapis yang bertujuan untuk menangkap radiasi matahari sekaligus mengurangi kerugian panas yang mengalir ke udara luar. Beberapa kerugian kalor yang dianalisa, maka diperoleh nilai kerugian kalor yang cukup besar terdapat pada sisi atas kolektor akibat radiasi. Untuk kondisi tertentu dibutuhkan temperatur yang tinggi pada temperatur plat kolektor untuk memanaskan adsorben yang terdapat didalamnya, tetapi pada hal lain kondisi ini membuat nilai koefisien perpindahan kalor total pada bagian sisi atas menjadi semakin besar. Peningkatan nilai koefisien perpindahan panas total tersebut turut meningkatkan kehilangan kalor pada sisi bagian atas kolektor surya tipe plat datar. 
Gambar 5 menampilkan korelasi distribusi tekanan pada kolektor dengan intensitas radiasi surya.

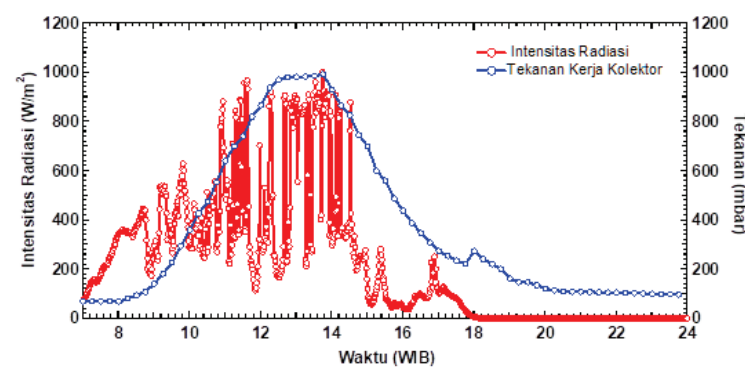

Gambar 5

Korelasi distribusi tekanan pada kolektor dengan intensitas radiasi surya

Tabel 4

Tekanan kerja saat pengujian

\begin{tabular}{l|l|l|l}
\hline \multirow{2}{*}{ Siklus } & \multirow{2}{*}{$\begin{array}{c}\text { Radiasi total } \\
\left(\mathrm{kJ} / \mathrm{m}^{2}\right)\end{array}$} & \multicolumn{2}{|c}{$\begin{array}{c}\text { Tekanan kerja } \\
(\mathrm{mb})\end{array}$} \\
\cline { 3 - 4 } & & \multicolumn{1}{|c}{ Maksimum } & \multicolumn{1}{c}{ Minimum } \\
\hline 1 & 13239 & 896,21 & 69,11 \\
\hline 2 & 14429 & 899,76 & 70,32 \\
\hline 3 & 15492 & 912,77 & 71,27 \\
\hline 4 & 17807 & 935,15 & 73,14 \\
\hline 5 & 12619 & 877,56 & 66,33 \\
\hline
\end{tabular}

Tampak bahwa perubahan tekanan pada kolektor turut dipengaruhi oleh pola intensitas radiasi matahari yang terjadi. Data pengukuran menunjukkan bahwa temperatur generasi atau pemanasan rata-rata terjadi sekitar 9 jam dan 15 jam adalah proses pendinginan serta adsorpsi. Pada pengujian ini diperoleh temperatur kolektor maksimum sebesar $127,85^{\circ} \mathrm{C}$ dengan intensitas radiasi maksimum $1048,10 \mathrm{~W} / \mathrm{m}^{2}$ yang terjadi pada siklus keempat. Untuk penelitian ini juga dilakukan pengukuran terhadap tekanan kerja di dalam mesin pendingin adsorpsi yang dapat dilihat pada tabel 4. Pada penelitian ini pengukuran tekanan kerja dilakukan dengan menggunakan manometer vakum digital yang dapat merekam perubahan tekanan yang terjadi selama 24 jam. Data hasil pengukuran menunjukkan bahwa tekanan kerja mesin pendingin saat pengujian cukup bervariasi. Selama pengujian diperoleh tekanan kerja berkisar 66,33-935,15 milibar. Data pengukuran dan pengujian menunjukkan bahwa tekanan kerja maksimum selama lima siklus umumnya terjadi pada pukul 12.27 WIB14.29 WIB, sedangkan tekanan kerja minimum terjadi pada pukul 03.59 WIB-06.40 WIB. Untuk penelitian ini diamati juga kondisi perubahan temperatur air sebagai media yang didinginkan. Selama proses pengujian diperoleh temperatur air minimum yang dapat dicapai saat proses adsorpsi sebesar $1,88^{\circ} \mathrm{C}$. Data hasil pengujian menunjukkan bahwa proses pemanasan dan desorpsi umumnya terjadi dari pukul 08.00 WIB hingga berakhir sekitar pukul 16.25 WIB-17.10 WIB atau berlangsung sekitar 7-9 jam. Proses pendinginan dan proses adsorpsi umumnya terjadi dari pukul 16.25 WIB-17.10 WIB hingga pukul 08.00 WIB atau berlangsung sekitar 12-15 jam.

\section{Kinerja Mesin Pendingin Adsorpsi}

Untuk menentukan karakteristik dari mesin pendingin adsorpsi tenaga surya, maka dapat ditinjau dari nilai COP yang diperoleh. Besarnya nilai COP selama pengujian dapat dilihat pada tabel 5. Besarnya nilai COP yang diperoleh dari hasil pengujian selama lima siklus adalah berkisar 0,0318-0,0449. Tampak bahwa nilai COP yang diperoleh sesuai dengan rentang nilai COP yang dihasilkan oleh mesin pendingin adsorpsi tenaga surya seperti yang dikemukakan oleh Alghoul (2006) yang nilainya berkisar dari 0,01 hingga 0,2 .

Tabel 5.

Nilai COP yang diperoleh selama pengujian

\begin{tabular}{l|l|l|l}
\hline \multirow{2}{*}{ Siklus } & \multicolumn{2}{c}{ Temperatur air $\left({ }^{\circ} \mathrm{C}\right)$} & \multicolumn{1}{c}{ COP } \\
\cline { 2 - 3 } & Maksimum & \multicolumn{1}{c}{ Minimum } & \\
\hline 1 & 25,70 & 3,24 & 0,0428 \\
2 & 25,55 & 3,09 & 0,0392 \\
3 & 25,88 & 3,42 & 0,0365 \\
4 & 24,34 & 1,88 & 0,0318 \\
5 & 25,36 & 2,90 & 0,0449 \\
\hline
\end{tabular}

Secara umum nilai COP mesin pendingin adsorpsi tenaga surya lebih rendah dari mesin pendingin siklus kompresi uap. Hal ini disebabkan sumber energi untuk mesin pendingin adsorpsi adalah energi surya 
sedangkan siklus kompresi uap menggunakan sumber energi listrik untuk menggerakkan kompresor. Sumber energi panas untuk mesin pendingin adsorpsi terutama yang digerakkan oleh tenaga surya umumnya memiliki temperatur di bawah $150^{\circ} \mathrm{C}$ dan intensitas radiasinya tidak konstan. Energi matahari tersebut disimpan oleh kolektor surya dan digunakan untuk memanaskan adsorben agar dapat melepaskan refrijeran dari adsorben pada saat proses desorpsi terjadi. Bila semakin besar energi panas yang diterima adsorben maka temperatur adsorben semakin tinggi dan semakin banyak refrijeran metanol yang dilepaskan oleh adsorben sehingga jumlah metanol yang tersimpan di evaporator semakin banyak. Semakin banyak jumlah metanol yang terdapat di wadah evaporator, maka efek pendinginan akan semakin bertambah. Selain itu proses perpindahan panas berupa pendinginan permukaan kolektor terjadi secara konveksi alami yang dipengaruhi kondisi cuaca. Perlu diketahui, pada mesin pendingin adsorpsi tenaga surya bahwa laju perpindahan panas dan massa yang terjadi di dalam adsorber cukup rendah sehingga dibutuhkan waktu yang lama untuk proses satu siklus. Kondisi inilah yang membuat nilai COP mesin pendingin adsorpsi yang digerakkan tenaga surya lebih rendah dari mesin pendingin siklus kompresi uap yang digerakkan oleh tenaga listrik.

Berdasarkan analisa data eksperimental diperoleh bahwa parameter utama yang mempengaruhi karakteristik kinerja mesin pendingin adsorpsi tenaga surya yang diuji adalah jumlah radiasi surya yang diterima kolektor saat pengujian, lamanya waktu proses untuk satu siklus, dan performansi kolektor. Pertama, fluktuasi radiasi surya dipengaruhi oleh kondisi langit seperti cerah (bright), berawan (cloudy), dan cerah yang diiringi hujan (rain with bright). Radiasi surya yang diterima oleh permukaan kolektor setiap siklus umumnya membuat temperatur kolektor maksimum di bawah temperatur $150^{\circ} \mathrm{C}$ dan hal ini turut mempengaruhi kemampuan dari adsorben dalam melepaskan metanol saat proses desorpsi. Kedua, mengenai keberadaan gas yang tidak diinginkan (unwanted gasses) sangat berhubungan dengan proses pemvakuman yang dilakukan. Menurut Eric (1998), umumnya mesin pendingin adsorpsi yang menggunakan refrijeran metanol memiliki tekanan operasional normal berkisar 20 mbar hingga 200 mbar. Tekanan operasional dari mesin pendingin adsorpsi yang diuji diperoleh berkisar 66,33 - 935,15 mbar. Ketiga, mengenai performansi kolektor dimana besarnya kerugian panas saat proses radiasi perlu diminimalisir. Pada kondisi lain diperlukan perbaikan dalam proses pendinginan kolektor yang terjadi secara konveksi alami agar efisiensi kolektor dapat meningkat. Selama proses pendinginan maka diperlukan temperatur kolektor serendah mungkin agar adsorben dapat menyerap seluruh metanol saat proses desorpsi terjadi.

\section{Korelasi Kondisi Cuaca Terhadap Efisiensi Kolektor Surya}

Tabel 6 menunjukkan kondisi cuaca untuk penghitungan efisiensi kolektor yang diperoleh dari hasil pengukuran selama pengujian.

Tabel 6.

Kondisi cuaca untuk penghitungan efisiensi kolektor surya

\begin{tabular}{l|l|l|l|l}
\hline Siklus & \multicolumn{2}{c}{$\begin{array}{c}\text { Radiasi maksimum }(\mathrm{W} / \\
\left.\mathrm{m}^{2}\right)\end{array}$} \\
\hline 1 & 1000,60 & 34,62 & 58,60 & \multicolumn{2}{c}{$\begin{array}{c}\text { Temperatur udara } \\
\left({ }^{\circ} \mathrm{C}\right)\end{array}$} & 62,30 & 53,13 \\
2 & 948,10 & 34,55 & 61,10 & 52,51 \\
3 & 960,60 & 33,39 & 43,80 & 52,12 \\
4 & 1048,10 & 34,89 & 67,50 & 53,92 \\
5 & 1009,40 & 32,51 & 52,11 \\
\hline
\end{tabular}


Selama proses pengujian diperoleh efisiensi kolektor maksimum sebesar $53,92 \%$ saat radiasi maksimum 1048,1 W/m². Berdasarkan fungsi statistik yang digunakan maka diperoleh korelasi parameter cuaca dengan efisiensi kolektor tipe plat datar yang diuji. Tabel 7 menunjukkan bahwa terdapat korelasi yang signifikan antara efisiensi kolektor terhadap radiasi surya sebesar 0,712 . Sebagai tambahan juga diuji efek cuaca terhadap efisiensi kolektor dengan menggunakan analisis regresi berganda. Diperoleh koefisien determinasi $\left(\mathrm{R}^{2}\right)$ sebesar 0,96 yang menunjukkan bahwa pengaruh kondisi cuaca terhadap efisiensi kolektor sebesar $96 \%$.

Tabel 7.

Korelasi parameter cuaca terhadap efisiensi kolektor surya

\begin{tabular}{l|l|l|l|l}
\hline \multicolumn{1}{c}{$\mathrm{I}_{\max }$} & \multicolumn{1}{c}{$\mathrm{T}_{\mathrm{u}}$} & \multicolumn{1}{c}{$\phi_{\mathrm{u}}$} & $\eta_{\mathrm{c}}$ \\
\hline $\mathrm{I}_{\max }$ & 1 & & & \\
$\mathrm{~T}_{\mathrm{u}}$ & 0.151 & 1 & & \\
$\phi_{\mathrm{u}}$ & -0.641 & -0.720 & 1 & \\
$\eta_{\mathrm{c}}$ & 0.712 & 0.798 & -0.926 & 1 \\
\hline
\end{tabular}

dimana $\mathrm{I}_{\max }$ adalah radiasi maksimum, $\mathrm{T}_{\mathrm{u}}$ adalah temperatur udara, $\phi_{\mathrm{u}}$ adalah kelembaban udara, dan $\eta_{c}$ adalah efisiensi kolektor.

\section{SIMPULAN}

Pada penelitian ini telah berhasil dirakit kolektor tipe plat datar untuk mesin pendingin adsorpsi tenaga surya dan diuji kinerjanya. Berdasarkan data eksperimental diperoleh bahwa kinerja dari kolektor tipe plat datar sangat mempengaruhi sistem operasional mesin pendingin adsorpsi tenaga surya. Begitu juga kinerja dari kolektor tipe plat datar yang digunakan sangat dipengaruhi oleh kondisi cuaca saat pengujian. Performansi atau efisiensi kolektor surya tipe plat datar yang diperoleh selama pengujian cukup bervariasi. Besarnya nilai efisiensi kolektor dipengaruhi oleh beberapa parameter seperti radiasi matahari yang diterima kolektor, luas permukaan kolektor, dan kerugian kalor total. Nilai efisiensi kolektor surya yang diperoleh selama pengujian berkisar 52,11-53,92\%. Hasil kajian statistik menyatakan bahwa besarnya pengaruh kondisi cuaca terhadap efisiensi kolektor adalah $96 \%$. Nilai COP yang diperoleh selama pengujian mesin pendingin adsorpsi berkisar 0,0318-0,0449.

\section{UCAPAN TERIMAKASIH}

Penulis mengucapkan terimakasih kepada DRPM Direktorat Jenderal Pendidikan Tinggi atas dana penelitian tahun 2018 yang diberikan sehingga kegiatan ini dapat diselesaikan dengan baik.

\section{DAFTAR PUSTAKA}

Alghoul, M. A., M. Y. Sulaiman, B. Z. Azmi., dan M. A. Wahab. 2006. Advances on multi-purpose solar adsorption systems for domestic refrigeration and water heating, Elsevier Journal.

Duffie, J. A. 2006. Solar Engineering of Thermal Processes. $3^{\text {rd }}$ Edition.

Eric, J. H. 1998. A Study of Thermal Decomposition of Methanol In Solar Powered Adsorption Refrigeration Systems. Solar Energy, 62(5):325-329.

Fan, Y. 2007. Review of Solar Adsorption Technologies. Development and Applications, Elsevier Journal.

Kalogirou, S. 2009. Solar Energy Engineering Process and Systems. $1^{\text {st }}$ Edition. The Cyprus University of Technology: Printed in the United States of America.

Li M., H. B. Huang, R. Z. Wang, L. L. Wang, W. M. Yang, dan W. D. Cai. 2005. Study on intermittent refrigeration phenomenon for solar solid adsorption refrigeration. Applied Thermal Engineering, 25:1614-1622,

Mahesh, A. 2017. Solar collectors and adsorption materials aspects of system. Renewable and Sustainable Energy Reviews, 73: 1300-1312.

Mehdi Z., G. Yogi, dan S. Elias. 2015. A review of solar thermo-mechanical refrigeration and cooling methods. Renewable and Sustainable Energy Reviews, 51:1428 - 1445. 
Musrowati L., Suwarno, Hadisusanto, D. T. Salahudin, dan H. N. Kamiso. 2014. Adsorpsi Pencemaran Limbah Cair Industri Penyamakan Kulit oleh Kitosan yang Melapisi Arang Aktif Tempurung. Jurnal TeknoSains, 3(2): 132-141.

Meunier, F. 1998. Solid Sorption Heat Powered Cycles for Cooling and Heat Pumping Application. Appl Therm Eng, 18: 715 - 729.

Saha B. B., I. I. El-Sharkawy, A. Chakraborty, dan S. Koyama. 2007. Study on an activated carbon fibre ethanol adsorption chiller: Part II e performance evaluation. International Journal of Refrigeration 30: 90 -102.

Saman et al. 2017. A review on the applications of porous materials in solar energy systems. Renewable and Sustainable Energy Reviews. 73: 1198-1210.

Sitorus T. B., F. H. Napitupulu, dan H. Ambarita. 2016. Experimental Study of Solar Refrigerator System Using Activated Alumina and Methanol Adsorption Pair. International Journal of Technology, IJTech Journal, 7(5): 910920.
Sitorus T. B., F. H. Napitupulu, dan H. Ambarita. 2017. A Study on Adsorption Refrigerator Driven by Solar Collector Using Indonesian Activated Carbon. J. Eng. Technol. Sci., 49(5): 657-670.

Sitorus T. B., H. Ambarita, F. Ariani, dan T. Sitepu. 2018. IOP Conf. Series: Materials Science and Engineering 309, 012089.

Umair M., A. Atsushi, dan U. Yuki. 2014. Performance Evaluation of a Solar Adsorption Refrigeration System with a Wing Type Compound Parabolic Concentrator, Energies, 7: 1448-1466.

Wang L.W., R. Z. Wang, dan R.G. Oliveira. 2009. A review on adsorption working pairs for refrigeration. Renewable and Sustainable Energy Reviews, 13: 518-534.

Watheq, K. S. H. 2008. Solar Energy Refrigeration by Liquid-Solid Adsorption Technique. Thesis, Egypt. 